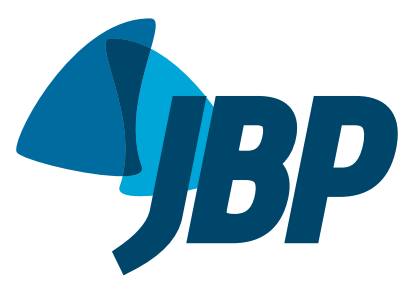

1. Curso de Medicina, Universidade Federal do Maranhão, São Luís (MA) Brasil.

2. Força Aérea Brasileira, Canoas (RS) Brasil.

3. Departamento de Morfologia Universidade Federal do Maranhão, São Luís (MA) Brasil.

Submitted: 22 February 2016 Accepted: 7 July 2016

Study carried out at the Curso de Medicina, Universidade Federal do Maranhão, São Luís (MA) Brasil.

\section{Temporal analysis of reported cases of tuberculosis and of tuberculosis-HIV co- infection in Brazil between 2002 and 2012}

\author{
Renato Simões Gaspar ${ }^{1}$, Natália Nunes ${ }^{1}$, Marina Nunes², \\ Vandilson Pinheiro Rodrigues ${ }^{3}$
}

\begin{abstract}
Objective: To investigate the reported cases of tuberculosis and of tuberculosis-HIV co-infection in Brazil between 2002 and 2012. Methods: This was an observational study based on secondary time series data collected from the Brazilian Case Registry Database for the 2002-2012 period. The incidence of tuberculosis was stratified by gender, age group, geographical region, and outcome, as was that of tuberculosisHIV co-infection. Results: Nationally, the incidence of tuberculosis declined by $18 \%$, whereas that of tuberculosis-HIV co-infection increased by $3.8 \%$. There was an overall decrease in the incidence of tuberculosis, despite a significant increase in that of tuberculosis-HIV co-infection in women. The incidence of tuberculosis decreased only in the 0- to 9-year age bracket, remaining stable or increasing in the other age groups. The incidence of tuberculosis-HIV co-infection increased by $209 \%$ in the $\geq 60$-year age bracket. The incidence of tuberculosis decreased in all geographical regions except the south, whereas that of tuberculosis-HIV co-infection increased by over $150 \%$ in the north and northeast. Regarding the outcomes, patients with tuberculosis-HIV coinfection, in comparison with patients infected with tuberculosis only, had a $48 \%$ lower chance of cure, a $50 \%$ greater risk of treatment nonadherence, and a $94 \%$ greater risk of death from tuberculosis. Conclusions: Our study shows that tuberculosis continues to be a relevant public health issue in Brazil, because the goals for the control and cure of the disease have yet to be achieved. In addition, the sharp increase in the incidence of tuberculosis-HIV co-infection in women, in the elderly, and in the northern/northeastern region reveals that the population of HIV-infected individuals is rapidly becoming more female, older, and more impoverished.
\end{abstract}

Keywords: Tuberculosis/epidemiology; HIV infections/epidemiology; Comorbidity.

\section{INTRODUCTION}

Tuberculosis is an infectious disease caused by $\mathrm{MycO}$ bacterium tuberculosis and continues to be a prevalent communicable disease in underdeveloped countries. Although there is treatment and means of prevention, approximately 9 million new cases are reported annually worldwide. Brazil is one of the 22 countries that collectively account for $80 \%$ of the global tuberculosis burden, with approximately 4,500 deaths from tuberculosis each year. In 2009 alone, 72,000 new cases were reported, which corresponds to an incidence rate of $38 / 100,000$ population. (1) These data demonstrate the severity of the tuberculosis problem in Brazil.

M. tuberculosis is transmitted by exhalation of infectious droplets, and its infectivity is directly related to the immune status of contacts. ${ }^{(2)}$ Chief among the factors contributing to the transmission and manifestation of tuberculosis are conurbations, poor sanitary conditions, limited access to health care, inadequate nutrition, and presence of other diseases, such as alcoholism, diabetes, and, in particular, HIV infection. ${ }^{(1)}$ Therefore, socioeconomically disadvantaged populations are at increased risk of contracting tuberculosis.

In the 1980s, with the advent of AIDS in the world, the tuberculosis problem worsened again. The presence of HIV resulted in tuberculosis changing from an endemic to an epidemic disease. The rate of tuberculosis-HIV co-infection has increased, and tuberculosis-HIV co-infection has been changing the epidemiological and prognostic aspects of tuberculosis. ${ }^{(1,3,4)}$ The mortality rate from tuberculosis increases by 2.4 - to 19 -fold in patients with tuberculosis-HIV co-infection, in comparison with HIV-negative patients. ${ }^{(5)}$ In addition, an analysis on the relationship between tuberculosis and HIV in Brazil, performed by Jamal et al., ${ }^{(6)}$ pointed out that the risk of developing tuberculosis is $10 \%$ per year for HIV-positive individuals, whereas, for HIV-negative patients, that risk is $10 \%$ over the course of their lifetime.

On the basis of clinical and epidemiological data, the World Health Organization (WHO), in 1993, designated tuberculosis as a priority in health policies. In Brazil, three years earlier, the Ministério da Saúde (MS, National Ministry of Health) had launched the Plano Emergencial

Correspondence to:

Vandilson Pinheiro Rodrigues. Departamento de Morfologia, Universidade Federal do Maranhão, Avenida dos Portugueses, S/N, Campus Universitário do Bacanga, CEP 65085-580, São Luís, MA, Brasil.

Tel.: 5598 98141-5836. E-mail: vandilson@hotmail.com

Financial support: None. 
para o Controle da Tuberculose (Emergency Plan for Tuberculosis Control), in which the implementation of a supervised treatment-a groundbreaking treatment worldwide-was recommended. (7) In 2003, the Brazilian MS declared tuberculosis to be one of the five diseases that are a priority for control in Brazil, including it in various action plans, such as Pacto pela Vida (Pact for Life), Mais Saúde (More Health), and Programação das Ações de Vigilância em Saúde (Programming of Health Surveillance Actions), and bringing information and efforts together in the Programa Nacional de Controle da Tuberculose (PNCT, Brazilian National Tuberculosis Control Program). Among the main objectives of the PNCT are the established goal of achieving a cure rate of $85 \%$ and an incidence rate below 25.6 cases $/ 100,000$ population by 2015 , as well as the decrease in the rate of treatment nonadherence and the prevention of the emergence of resistant bacilli, so as to thus enable effective control of tuberculosis in Brazil. $(8,9)$

In view of the epidemiological importance of tuberculosis and the lack of recent analyses of data collected from the Sistema de Informação de Agravos de Notificação (SINAN, Brazilian Case Registry Database), it is essential that the tuberculosis problem in Brazil and its relationship with HIV be studied. Such studies will provide a basis for the development of new guidelines. Therefore, the present study investigated, through data obtained from SINAN for the 2002-2012 period, the evolution of tuberculosis and of tuberculosis-HIV co-infection in Brazil for different clinical and epidemiological variables.

\section{METHODS}

This was an observational study based on secondary time series data collected directly from SINAN, through the national database of the Brazilian Unified Health Care System, for the 2002-2012 period. The dependent variable was the incidence rate of tuberculosis and that of tuberculosis-HIV co-infection over the analysis period, calculated as the number of new cases reported or recorded as "does not know" per year of diagnosis, as recommended by SINAN, divided by the number of inhabitants in the same period per region of residence, using the 100,000 constant. The number of inhabitants per region was obtained from census data (2000 and 2010) and inter-census population estimates, all of which were provided by the Instituto Brasileiro de Geografia e Estatística (Brazilian Institute of Geography and Statistics). Only patients who were reported as HIV-positive were considered to have HIV infection. The independent variables collected included gender (male and female); age group (0-9, 10-19, 20-39, 40-59, and $\geq 60$ years); outcome (cure, nonadherence, death from tuberculosis, and multidrug-resistant tuberculosis); and geographical region of residence (north, northeast, southeast, south, and central-west).

The data were summarized as incidence rates, measures of central tendency, measures of growth, and proportions. The data were tabulated into a Microsoft
Excel 2010 spreadsheet and subsequently analyzed using the Graphpad Prism statistical software program, version 5.0 (GraphPad Inc., San Diego, CA, USA). Prais-Winsten generalized linear regression was used to analyze growth trends in the time series. This procedure made it possible to determine whether the variations were upward, downward, or stable, by analyzing the measures of growth and the significance level ( $p<$ $0.05)$. Total variation was calculated as the difference in proportion between the incidence in 2002 and the incidence in 2012. In addition, categorical variables were tested for associations by using odds ratios and the chi-square test. For all tests, the significance level was set at $95 \%$.

\section{RESULTS}

Table 1 shows the data obtained from SINAN regarding the crude and relative incidence of tuberculosis and of tuberculosis-HIV co-infection, as well as the ratio between the two incidences. Over the study period, there was a decrease in the incidence of tuberculosis, both in absolute numbers and per 100,000 population. In terms of total variation, the crude incidence of tuberculosis decreased by $9.66 \%$, whereas the relative incidence decreased by $18.66 \%$. As for tuberculosis-HIV co-infection, the crude incidence increased by $15.19 \%$, whereas the incidence per 100,000 population increased by almost $4 \%$. Nevertheless, the tuberculosis-HIV co-infection/tuberculosis ratio increased by $27.51 \%$ over the analysis period, indicating the growing importance of HIV in the epidemiology of tuberculosis.

Table 2 presents the incidence per 100,000 population of tuberculosis and of tuberculosis-HIV co-infection in each year studied, by gender. There was a reduction in the incidence of tuberculosis in men $(-14.52 \%)$ and in women $(-25.41 \%)$. However, the incidence of tuberculosis-HIV co-infection increased by almost $8 \%$ in women, a variation that is $5.4 \%$ higher than that found in males. This reveals that the population of HIV-infected individuals is rapidly becoming more female.

Table 3 shows the incidence per 100,000 population of tuberculosis and of tuberculosis-HIV co-infection in each year studied, by age group. There was statistical significance for the incidence of tuberculosis only in the 0 - to 9-year and the 40- to 59-year age groups. A substantial reduction of $31 \%$ can be seen in the 0 - to 9 -year age group, being in contrast with the almost $11 \%$ increase observed in the 40 - to 59 -year age group. The picture is reversed when looking at the behavior of tuberculosis-HIV co-infection. There was a reduction only in the 0 - to 9 -year age group $(-36.36 \%)$, whereas there were substantial increases in the other age groups: more than $50 \%$ in the 10 - to 19 -year age group; $11.32 \%$ in the 20 - to 39 -year age group; and over $76 \%$ in the 40 - to 49 -year age group. The most remarkable finding was the $209 \%$ increase in the incidence of tuberculosis-HIV co-infection in the $\geq 60$-year age group. 
Table 1. Incidence of reported cases of tuberculosis and of tuberculosis-HIV co-infection, Brazil, 2002-2012.

\begin{tabular}{|c|c|c|c|c|c|}
\hline \multirow[t]{2}{*}{ Year } & \multicolumn{2}{|r|}{ TB } & \multicolumn{2}{|c|}{ TB-HIV co-infection } & \multirow{2}{*}{$\begin{array}{c}\text { TB-HIV } \\
\text { co-infection/ } \\
\text { TB ratio, \% }\end{array}$} \\
\hline & $\begin{array}{c}\text { Crude } \\
\text { incidence }\end{array}$ & $\begin{array}{c}\text { Incidence/ } \\
100,000 \text { population }\end{array}$ & $\begin{array}{c}\text { Crude } \\
\text { incidence }\end{array}$ & $\begin{array}{c}\text { Incidence/ } \\
100,000 \text { population }\end{array}$ & \\
\hline 2002 & 77,507 & 44.38 & 5,943 & 3.40 & 7.67 \\
\hline 2003 & 78,599 & 44.44 & 6,068 & 3.43 & 7.72 \\
\hline 2004 & 77,691 & 43.38 & 5,835 & 3.26 & 7.51 \\
\hline 2005 & 76,751 & 41.67 & 5,841 & 3.17 & 7.61 \\
\hline 2006 & 71,831 & 38.46 & 6,162 & 3.30 & 8.58 \\
\hline 2007 & 71,629 & 37.83 & 6,398 & 3.38 & 8.93 \\
\hline 2008 & 73,427 & 38.72 & 6,630 & 3.50 & 9.03 \\
\hline 2009 & 72,895 & 38.07 & 6,771 & 3.54 & 9.29 \\
\hline 2010 & 71,390 & 37.42 & 7,037 & 3.69 & 9.86 \\
\hline 2011 & 73,168 & 38.03 & 7,150 & 3.72 & 9.77 \\
\hline 2012 & 70,023 & 36.10 & 6,846 & 3.53 & 9.78 \\
\hline Total variation, \% & -9.66 & -18.66 & 15.19 & 3.82 & 27.51 \\
\hline $\mathrm{p}$ & $<0.05$ & $<0.05$ & $<0.05$ & $<0.05$ & $<0.05$ \\
\hline
\end{tabular}

TB: tuberculosis.

Table 2. Incidence of reported cases of tuberculosis and of tuberculosis-HIV co-infection, by gender, Brazil, $2002-2012$.

\begin{tabular}{|c|c|c|c|c|}
\hline \multirow[t]{2}{*}{ Year } & \multicolumn{2}{|c|}{$\begin{array}{l}\text { Incidence of TB/ } \\
100,000 \text { population }\end{array}$} & \multicolumn{2}{|c|}{$\begin{array}{c}\text { Incidence of TB-HIV co-infection/ } \\
100,000 \text { population }\end{array}$} \\
\hline & Males & Females & Males & Females \\
\hline 2002 & 57.64 & 31.44 & 4.93 & 1.92 \\
\hline 2003 & 57.69 & 31.58 & 4.92 & 1.99 \\
\hline 2004 & 56.64 & 30.50 & 4.64 & 1.92 \\
\hline 2005 & 54.66 & 29.04 & 4.49 & 1.89 \\
\hline 2006 & 50.48 & 26.80 & 4.67 & 1.97 \\
\hline 2007 & 50.33 & 25.75 & 4.84 & 1.97 \\
\hline 2008 & 51.69 & 26.19 & 4.96 & 2.08 \\
\hline 2009 & 50.91 & 25.67 & 5.00 & 2.12 \\
\hline 2010 & 50.52 & 24.86 & 5.27 & 2.17 \\
\hline 2011 & 51.58 & 25.04 & 5.34 & 2.16 \\
\hline 2012 & 49.27 & 23.45 & 5.05 & 2.07 \\
\hline Total variation, \% & -14.52 & -25.41 & 2.43 & 7.81 \\
\hline $\mathrm{p}$ & $<0.05$ & $<0.05$ & $<0.05$ & $<0.05$ \\
\hline
\end{tabular}

TB: tuberculosis.

Table 3. Incidence of reported cases of tuberculosis and of tuberculosis-HIV co-infection, by age group in years, Brazil, 2002-2012.

\begin{tabular}{|c|c|c|c|c|c|c|c|c|c|c|}
\hline \multirow[t]{3}{*}{ Year } & \multicolumn{5}{|c|}{$\begin{array}{l}\text { Incidence of TB/ } \\
100,000 \text { population }\end{array}$} & \multicolumn{5}{|c|}{$\begin{array}{c}\text { Incidence of TB-HIV co-infection/ } \\
100,000 \text { population }\end{array}$} \\
\hline & \multicolumn{5}{|c|}{ Age group, years } & \multicolumn{5}{|c|}{ Age group, years } \\
\hline & $0-9$ & 10-19 & 20-39 & $40-59$ & $\geq 60$ & $0-9$ & 10-19 & 20-39 & $40-59$ & $\geq 60$ \\
\hline 2002 & 6.28 & 18.78 & 102.31 & 70.79 & 29.12 & 0.33 & 0.32 & 11.51 & 5.00 & 0.32 \\
\hline 2003 & 5.96 & 18.31 & 102.22 & 71.76 & 29.28 & 0.27 & 0.33 & 11.17 & 5.50 & 0.37 \\
\hline 2004 & 5.40 & 17.43 & 99.96 & 70.77 & 28.43 & 0.33 & 0.37 & 10.32 & 5.36 & 0.38 \\
\hline 2005 & 5.07 & 16.62 & 95.25 & 68.63 & 27.63 & 0.25 & 0.29 & 9.83 & 5.52 & 0.41 \\
\hline 2006 & 4.52 & 13.85 & 87.34 & 65.05 & 25.73 & 0.31 & 0.37 & 9.52 & 6.18 & 0.59 \\
\hline 2007 & 4.78 & 15.69 & 95.74 & 69.54 & 27.66 & 0.22 & 0.38 & 10.79 & 7.12 & 0.61 \\
\hline 2008 & 4.45 & 16.16 & 96.73 & 70.37 & 28.14 & 0.22 & 0.47 & 10.74 & 7.10 & 0.68 \\
\hline 2009 & 4.62 & 16.12 & 100.81 & 73.23 & 28.25 & 0.24 & 0.50 & 11.24 & 7.82 & 0.89 \\
\hline 2010 & 4.59 & 17.32 & 100.52 & 74.20 & 32.42 & 0.23 & 0.50 & 11.57 & 8.19 & 0.93 \\
\hline 2011 & 4.68 & 18.41 & 112.27 & 82.32 & 33.78 & 0.24 & 0.60 & 13.49 & 9.54 & 0.90 \\
\hline 2012 & 4.32 & 17.40 & 106.12 & 78.34 & 31.37 & 0.21 & 0.49 & 12.80 & 8.83 & 0.99 \\
\hline Total variation, \% & -31.21 & -7.35 & 3.72 & 10.67 & 7.73 & -36.36 & 53.13 & 11.21 & 76.60 & 209.38 \\
\hline $\mathrm{p}$ & $<0.05$ & 0.73 & 0.24 & $<0.05$ & 0.06 & $<0.05$ & $<0.05$ & 0.05 & $<0.05$ & $<0.05$ \\
\hline
\end{tabular}

TB: tuberculosis. 
Table 4 presents the data regarding the incidence per 100,000 population of tuberculosis and of tuberculosis-HIV co-infection in the years under study, by geographical region. In terms of total variation, the incidence of tuberculosis decreased by $20.19 \%$ in the southeast, by $20.14 \%$ in the northeast, by $12.37 \%$ in the north, and by $7.80 \%$ in the central-west. In the south, that incidence remained stable.

Also according to Table 4, the incidence of tuberculosis-HIV co-infection increased substantially in the north and northeast, with total variation exceeding $150 \%$ over the 11 -year period studied. In the south, there were no significant differences in incidence, whereas, in the central-west, there was an increase of almost $47 \%$. In the southeast, unlike in the other regions, there was a $25 \%$ reduction in the rates of tuberculosis-HIV co-infection.

Regarding the outcomes, Table 5 shows that the cure rate in patients with tuberculosis-HIV co-infection was $50.74 \%$, whereas, in patients infected with tuberculosis only, that rate was higher: $71.10 \%$. Calculation of odds ratios indicated that tuberculosis-HIV co-infection decreased the chance of being cured of tuberculosis by $58 \%$. In addition, the rate of treatment nonadherence was $13.60 \%$ in patients with tuberculosis-HIV co-infection, compared with $9.52 \%$ in patients infected with tuberculosis only. Therefore, HIV infection increased the risk of treatment nonadherence by $50 \%$ in patients infected with tuberculosis. Taken together, the previous data indicate that patients with tuberculosis-HIV co-infection, in comparison with patients infected with tuberculosis only, had a $94 \%$ greater risk of dying from tuberculosis. Nevertheless, tuberculosis-HIV co-infection was not associated with multidrug-resistant tuberculosis.

\section{DISCUSSION}

The data from the present study show that there was a significant decrease in the incidence of tuberculosis in Brazil between 2002 and 2012. This decrease was

Table 4. Incidence of reported cases of tuberculosis and of tuberculosis-HIV co-infection, by geographical region, Brazil, 2002-2012.

\begin{tabular}{|c|c|c|c|c|c|c|c|c|c|c|}
\hline \multirow[t]{2}{*}{ Year } & \multicolumn{5}{|c|}{$\begin{array}{l}\text { Incidence of TB/ } \\
100,000 \text { population }\end{array}$} & \multicolumn{5}{|c|}{$\begin{array}{l}\text { Incidence of TB-HIV co-infection/ } \\
100,000 \text { population }\end{array}$} \\
\hline & $\mathbf{N}$ & NE & SE & $\mathbf{S}$ & CW & $\mathbf{N}$ & NE & SE & $\mathbf{S}$ & CW \\
\hline 2002 & 51.03 & 44.15 & 48.73 & 34.64 & 26.29 & 1.39 & 0.94 & 4.8 & 5.42 & 1.49 \\
\hline 2003 & 49.97 & 46.14 & 47.27 & 35.41 & 27.08 & 1.96 & 1.28 & 4.55 & 5.41 & 1.58 \\
\hline 2004 & 50.6 & 45.9 & 45.52 & 34.08 & 24.7 & 1.64 & 1.48 & 4.21 & 5.04 & 1.49 \\
\hline 2005 & 47.32 & 45.54 & 42.9 & 32.32 & 25.34 & 1.95 & 1.46 & 3.95 & 5.03 & 1.68 \\
\hline 2006 & 46.05 & 41.03 & 40.53 & 30.48 & 24.27 & 1.96 & 1.56 & 4.47 & 4.69 & 1.67 \\
\hline 2007 & 45.01 & 39.49 & 40.68 & 31.83 & 23.13 & 2.27 & 1.88 & 4.14 & 5.23 & 2.08 \\
\hline 2008 & 44.69 & 38.13 & 40.37 & 31.84 & 22.8 & 3.18 & 2.05 & 4.01 & 5.71 & 1.97 \\
\hline 2009 & 47.78 & 38.85 & 41.01 & 33.21 & 21.91 & 3.41 & 2.19 & 4.00 & 5.58 & 2.06 \\
\hline 2010 & 40.88 & 33.95 & 36.45 & 30.35 & 20.98 & 3.83 & 2.48 & 3.93 & 6.08 & 2.03 \\
\hline 2011 & 46.42 & 37.7 & 41.48 & 33.26 & 23.08 & 3.67 & 2.64 & 3.97 & 5.92 & 2.04 \\
\hline 2012 & 44.72 & 35.26 & 38.89 & 32.06 & 24.24 & 3.81 & 2.7 & 3.59 & 5.48 & 2.19 \\
\hline Total variation, $\%$ & -12.37 & -20.14 & -20.19 & -7.45 & -7.80 & 174.10 & 187.23 & -25.21 & 1.11 & 46.98 \\
\hline $\mathrm{p}$ & $<0.05$ & $<0.05$ & $<0.05$ & 0.08 & $<0.05$ & $<0.05$ & $<0.05$ & $<0.05$ & 0.07 & $<0.05$ \\
\hline
\end{tabular}

TB: tuberculosis; N: north; NE: northeast; SE: southeast; S: south; and CO: central-west.

Table 5 . Association between tuberculosis-HIV co-infection and observed outcomes, Brazil, $2002-2012$.

\begin{tabular}{|c|c|c|c|c|}
\hline \multirow[t]{2}{*}{ Outcome } & \multicolumn{2}{|c|}{ Cases reported to SINAN, \% } & \multirow[t]{2}{*}{ OR (Cl 95\%) } & \multirow[t]{2}{*}{$\mathbf{p}$} \\
\hline & TB-HIV co-infection & $\mathrm{TB}^{\mathrm{a}}$ & & \\
\hline \multicolumn{5}{|l|}{ Cure } \\
\hline Yes & 50.74 & 71.10 & $0.42(0.41-0.42)$ & $<0.05$ \\
\hline No & 49.26 & 28.90 & Ref. & \\
\hline \multicolumn{5}{|l|}{ Nonadherence } \\
\hline Yes & 13.60 & 9.52 & $1.50(1.46-1.53)$ & $<0.05$ \\
\hline No & 86.40 & 90.48 & Ref. & \\
\hline \multicolumn{5}{|l|}{ Death from TB } \\
\hline Yes & 3.63 & 1.90 & $1.94(1.86-2.02)$ & $<0.05$ \\
\hline No & 96.37 & 98.10 & Ref. & \\
\hline \multicolumn{5}{|c|}{ Multidrug-resistant TB } \\
\hline Yes & 0.17 & 0.17 & $0.95(0.75-1.21)$ & 0.70 \\
\hline No & 99.83 & 99.83 & Ref. & \\
\hline
\end{tabular}

SINAN: Sistema de Informação de Agravos de Notificação (Brazilian Case Registry Database); TB: tuberculosis;

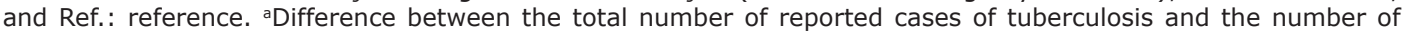
cases diagnosed as HIV-positive. 
found to be more prominent in women and children in all geographical regions except the south. In contrast, we found that the incidence rates of tuberculosis remain high in men aged between 20 and 59 years. In addition, the cure rates fall short of the goal established by the

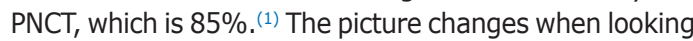
at tuberculosis-HIV co-infection. Not only did the total incidence of tuberculosis-HIV co-infection increased, but it was greater in women, in the elderly, and in residents of the northern and northeastern regions, which reveals that the population of HIV-infected individuals is rapidly becoming more female, older, and more impoverished. Finally, the data showed that, in patients with tuberculosis-HIV co-infection, the cure rates were lower, whereas the rates of treatment nonadherence and the rates of death were higher. The present study adds to the debate about the public policies to control tuberculosis and tuberculosis-HIV co-infection in Brazil, demonstrating the impact of those policies on our country and on at-risk populations, their possible shortcomings, and possible areas for improvement. Regarding the incidence of tuberculosis, we found a reduction both in absolute numbers and per 100,000 population. According to Guimarães et al.,(10) the incidence of tuberculosis decreased by $48.8 \%$ between 1990 and 2010 in Brazil, being as low as 43/100,000 population in the last year studied. That result supports our analysis that the incidence of tuberculosis has decreased. However, our data differ in that they show an increased incidence in some age groups and a less precipitous drop. This disparity between results may have been due to the use of different databases.

The same was not found for the incidence of tuberculosis-HIV co-infection, which in fact increased by $3.82 \%$ over the study period. It is clear that HIV has contributed to the growing number of cases of tuberculosis, ${ }^{(6,11)}$ especially because of the increased risk of contracting this disease, given the immunosuppression caused by the virus. $(2,6)$ Therefore, we found an increase of $27.51 \%$ in the tuberculosis-HIV co-infection/tuberculosis ratio over the study period, which underscores the significance of this co-infection for the adequate control of tuberculosis. In 2011, the Brazilian MS recognized that, given the high prevalence of tuberculosis-HIV co-infection and the increased rates of death from tuberculosis among HIV-positive patients, tuberculosis-HIV co-infection needed to be

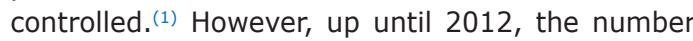
of reported cases of tuberculosis-HIV co-infection increased significantly, which emphasizes the need for more actions aimed at preventing the spread of HIV, as well as for treating and following co-infected patients more thoroughly.

When analyzed by gender, the incidence of tuberculosis was twice as high in males as in females. This finding substantiates the indication that, in Brazil, tuberculosis primarily affects males, ${ }^{(12)}$ in whom the risk of developing the disease is twice as high. ${ }^{(7)}$ It is necessary to comment that there was a greater reduction in the incidence of tuberculosis in females, probably because women take better care of their health. ${ }^{(13)}$ However, the incidence of tuberculosis-HIV co-infection was high in females, indicating a greater number of new HIV-positive women. These data support those of other studies conducted in Brazil that showed a higher incidence and prevalence of tuberculosis and HIV infection in males, as well as increased rates of tuberculosis-HIV co-infection, ${ }^{(3,14)}$ which is influenced by genetic, environmental, and immunological factors and of which better understanding would lead to advances in diagnosis that would favor the development of new technologies and treatments for both diseases. ${ }^{(15)}$

When analyzed by age group, the incidence of tuberculosis was found to have decreased by one third in children aged 0-9 years. This implies greater effectiveness of treatment and greater effectiveness of prophylaxis of contacts, as well as improvements in housing, sanitary conditions, quality of diet, and access to health care, including adherence to vaccination schedules, since these characteristics are intrinsically associated with the decrease in the incidence of tuberculosis, especially in children, ${ }^{(16)}$ although the diagnosis is difficult in such cases. ${ }^{(17)}$ However, in all other age groups, except the 10- to 19-year age group, there were increases in the incidence of tuberculosis, as was also found in the Brazilian literature until 2004.(18) In addition, we detected a substantial increase in the co-infection rate in the 10- to 19-year age group, as well as in others. In a study conducted in Brazil, dos Santos Dias et al. ${ }^{(19)}$ reported worse outcomes and greater likelihood of unfavorable results in patients co-infected with HIV. This leads us to a social problem: the economically active population is increasingly developing tuberculosis, which is more prevalent in marginalized and impoverished segments of society. ${ }^{(20)}$

The increase of $209 \%$ in the incidence of tuberculosis-HIV co-infection in the $\geq 60$-year age group requires the development of elderly-targeted public policies that encourage educational interventions and gradually act on the sexual issue and on the prevention of sexually transmitted diseases. In addition to the increase in the number of elderly in the population, the improvement in quality of life and the use of medications for erectile dysfunction have increased the prevalence of HIV infection, worsening the already existing public health problem. The elderly are known to be more susceptible to illness, because they have decreased immunity, as well as to have comorbidities and to be on polypharmacy, both of which are pointed out as risk factors for recurrence of tuberculosis. ${ }^{(21)}$ Therefore, the increased tuberculosis-HIV co-infection rate in this population implies higher mortality from tuberculosis. The study by Chaimowicz ${ }^{(22)}$ suggested that there will be a reduction in the tuberculosis-HIV co-infection rate in the $\geq 60$-year age group over the next 50 years. However, this will only be possible if public policies aimed at this population are implemented.

When analyzed by geopolitical regions in Brazil, the incidence of tuberculosis was found to have decreased in all regions except the south. This decrease may be 
directly related to the implementation of the $\mathrm{PNCT}^{(1)}$ in those regions, as well as to the fact that the WHO has declared tuberculosis a health emergency, expanding the disease control interventions. In contrast, the increase in the incidence of tuberculosis-HIV co-infection in all regions strengthens the notion that HIV infection is the major risk factor for the development of tuberculosis. ${ }^{(7)}$ The $150 \%$ increase found in the northern and northeastern regions reveals that the population of HIV-infected individuals is becoming more rural, which is an aggravating factor to the tuberculosis problem, because marginalized regions with poor social and health indicators are more vulnerable. ${ }^{(18,23)}$ Nevertheless, Prado et al. ${ }^{(24)}$ reported that patients co-infected with HIV were less likely to live in rural areas. Considering all the evidence, it is necessary to structure primary health care clinics so that they can meet the needs of those regions and to implement social development policies in those regions so that they are no longer vulnerable. It is of note that direct income transfer programs seem to contribute to increasing the cure rates for tuberculosis in Brazil.(25) Therefore, in order to achieve far-reaching and robust results, public health policies should address the various facets of the disease, such as social, economic, environmental, and clinical problems. ${ }^{(21,26-28)}$

After analyzing the temporal evolution of tuberculosis and of tuberculosis-HIV co-infection for different epidemiological profiles, we extracted the outcome data for the same period in order to assess the goals of the PNCT ${ }^{(1)}$ and the influence of tuberculosis-HIV co-infection on outcome. The difference in the cure rate between HIV-negative and HIV-positive patients is clear. Whereas the former had a cure rate of $71 \%$, the latter had a cure rate of only $50 \%$, which means that patients with tuberculosis-HIV co-infection had a $48 \%$ lower chance of cure than did HIV-negative patients. This relationship has been reported in other studies $^{(29,30)}$ and is related to the immunodeficiency caused by HIV in such patients, the time from diagnosis to treatment initiation, and the limited access to health care. ${ }^{(31)}$ Even after the launch of the PNCT and after the establishment of the WHO and the Brazilian MS goal of curing $85 \%$ of reported cases by 2015 , Brazil has not yet achieved this purpose, as shown by our analysis of the 2002-2012 period. (1)

The rates of treatment nonadherence for the reported cases of tuberculosis and of tuberculosis-HIV co-infection were $9 \%$ and $13 \%$, respectively, being similar to those found in previous studies. ${ }^{(18,20,29,32)}$ Although treatments are available free of charge in the public health care system, the dispensing of medications and treatment follow-up are performed at different places. In addition, the long duration and the side effects of the treatment favor nonadherence. ${ }^{(6)}$
The rate of death from tuberculosis was found to be almost 3-fold higher in patients with tuberculosis-HIV co-infection than in HIV-negative patients. These data are similar to those found in other studies ${ }^{(18,29)}$ and, once again, are related to the immune profile of HIV-positive patients ${ }^{(33)}$ and to the rates of treatment nonadherence, which are higher in this population, as demonstrated in the present study. Nevertheless, Dowdy et al. ${ }^{(34)}$ reported similar decreases in quality of life across groups of patients with tuberculosis, with HIV, and with tuberculosis-HIV co-infection, by using a validated self-assessment instrument. It is of note that we found no differences in the rate of multidrug-resistant tuberculosis between the groups. Although some studies support this finding, ${ }^{(7,18)}$ others suggest the opposite, and this information is relevant to disease outcome. (1,33,35,36) $^{-1}$

The major limitation of the present study is the use of secondary data, given that such data can affect the analysis, especially because of poor record completion. ${ }^{(37,38)}$ Therefore, it is essential to ensure the sensitivity and reliability of the SINAN data so that they can be safely used by researchers, health care managers, and health care professionals in an equal fashion nationwide.

In summary, our findings suggest, within the limits of this study, that the epidemiological behavior of the reported new cases of tuberculosis and that of the cases of tuberculosis-HIV co-infection showed opposite trends between 2002 and 2012. Infection with HIV is an important factor in the course of tuberculosis. This information is essential to the implementation of a policy aimed at informing the care of HIV-positive patients so that more effective monitoring measures can be made available. Conversely, despite advances in the treatment and prevention of HIV infection, it is necessary not to neglect the continued spread of this infection in Brazil, especially in women, in the elderly, and in less developed regions. In addition, it is necessary to expand the PNCT ${ }^{(1)}$ uniformly in the whole country so that it is possible to achieve the established goals, as well as to offer structured and effective care nationwide. Finally, encouraging and facilitating the functioning of primary health care clinics, through continuing education, that are apt to diagnose and treat tuberculosis is indispensable to improving data on this disease.

\section{ACKNOWLEDGMENTS}

We are grateful to the staff members of the Brazilian Unified Health Care System Open University of the Federal University of Maranhão for their support in conducting the study.

\section{REFERENCES}

Brasil. Ministério da Saúde. Secretaria de Vigilância em Saúde. Departamento de Vigilância Epidemiológica. Manual de recomendações para o controle da tuberculose no Brasil. Brasília:
Ministério da Saúde; 2011.

2. Orme IM, Robinson RT, Cooper AM. The balance between protective and pathogenic immune responses in the TB-infected lung. Nat 
Immunol. 2015;16(1):57-63. http://dx.doi.org/10.1038/ni.3048

3. Cheade Mde F, Ivo ML, Siqueira PH, Sá RG, Honer MR. Characterization of tuberculosis among HIV/AIDS patients at a referral center in Mato Grosso do Sul [Article in Portuguese]. Rev Soc Bras Med Trop. 2009;42(2):119-25.

4. Corbett EL, Watt CJ, Walker N, Maher D, Williams BG, Raviglione $M C$, et al. The growing burden of tuberculosis: global trends and interactions with the HIV epidemic. Arch Intern Med. 2003:163(9):1009-21. http://dx.doi.org/10.1001/archinte.163.9.1009

5. de Carvalho LG, Buani AZ, Zöllner MS, Scherma AP. Co-infection with Mycobacterium tuberculosis and human immunodeficiency virus: an epidemiological analysis in the city of Taubaté, Brazil. J Bras Pneumol. 2006;32(5):424-9. http://dx.doi.org/10.1590/S180637132006000500009

6. Jamal LF, Moherdaui F. Tuberculosis and HIV infection in Brazil: magnitude of the problem and strategies for control [Article in Portuguese]. Rev Saude Publica. 2007;41 Suppl 1:104-10. http:// dx.doi.org/10.1590/S0034-89102007000800014

7. Barbosa IR, Costa IC. The emergency of tuberculosis-HIV coinfection in Brazil [Article in Portuguese]. Hygea. 2012;8(15):232-44

8. Brasil. Ministério da Saúde. Programa Nacional de Controle da Tuberculose. Brasília: Ministério da Saúde; 2003.

9. Augusto CJ, Carvalho Wda S, Gonçalves AD, Ceccato Md, Miranda SS. Characteristics of tuberculosis in the state of Minas Gerais Brazil: 2002-2009. J Bras Pneumol. 2013;39(3):357-64. http://dx.doi. org/10.1590/S1806-37132013000300013

10. Guimarães RM, Lobo Ade P, Siqueira EA, Borges TF, Melo SC Tuberculosis, HIV, and poverty: temporal trends in Brazil, the Americas, and worldwide. J Bras Pneumol. 2012;38(4):511-7. http:// dx.doi.org/10.1590/S1806-37132012000400014

11. Ruffino-Netto A. Tuberculosis: the negleted calamity [Article in Portuguese]. Rev Soc Bras Med Trop. 2002;35(1):51-8. http://dx.doi. org/10.1590/S0037-86822002000100010

12. Maruza M, Albuquerque MF, Coimbra I, Moura LV, Montarroyos UR, Miranda Filho DB, et al. Risk factors for default from tuberculosis treatment in HIV-infected individuals in the state of Pernambuco, Brazil: a prospective cohort study. BMC Infect Dis. 2011;11:351. http://dx.doi.org/10.1186/1471-2334-11-351

13. Machin R, Couto MT, Silva GS, Schraiber LB, Gomes R, Figueiredo WS, et al. Concepts of gender, masculinity and healthcare: a study of primary healthcare professionals [Article in Portuguese]. Cien Saude Col. 2011;16(11):4503-12. http://dx.doi.org/10.1590/S141381232011001200023

14. Garrido Mda S, Bührer-Sékula S, Souza AB, Ramasawmy R, Quincó Pde L, Monte RL, et al. Temporal distribution of tuberculosis in the State of Amazonas, Brazil. Rev Soc Bras Med Trop. 2015;48 Supp 1:63-9. http://dx.doi.org/10.1590/0037-8682-0055-2014

15. Raghavan S, Alagarasu K, Selvaraj P. Immunogenetics of HIV and HIV associated tuberculosis. Tuberculosis (Edinb). 2012:92(1):18-30. http://dx.doi.org/10.1016/.tube.2011.08.004

16. Getahun H, Sculier D, Sismanidis C, Grzemska M, Raviglione M. Prevention, diagnosis, and treatment of tuberculosis in children and mothers: evidence for action for maternal, neonatal, and child health services. J Inf Dis. 2012;205 Suppl 2:S216-27. http://dx.doi. org/10.1093/infdis/jis009

17. Pedrozo C, Sant'Anna CC, March Mde F, Lucena SC. Efficacy of the scoring system, recommended by the Brazilian National Ministry of Health, for the diagnosis of pulmonary tuberculosis in children and adolescents, regardless of their HIV status. J Bras Pneumol. 2010;36(1):92-8

18. Bierrenbach $A L$, Gomes $A B$, Noronha $E F$, de Souza Mde F. Tuberculosis incidence and cure rates, Brazil, 2000-2004 [Article in Portuguese]. Rev Saude Publica. 2007:41 Suppl 1:24-33.

19. dos Santos Dias E, do Prado TN, da Silva Guimarães AL, Ramos MC Sales CM, de Fátima Almeida Lima E, et al. Childhood tuberculosis and human immunodeficiency virus status in Brazil: a hierarchical analysis. Int J Tuberc Lung Dis. 2015;19(11):1305-11. http://dx.doi. org/10.5588/ijtld.14.0619

20. Santos Neto M, Silva FL, Sousa KR, Yamamura M, Popolin MP Arcêncio RA. Clinical and epidemiological profile and prevalence of tuberculosis/HIV co-infection in a regional health district in the state of Maranhão, Brazil. J Bras Pneumol. 2012;38(6):724-32. http:// dx.doi.org/10.1590/S1806-37132012000600007
21. Oliveira HB, Moreira-Filho DC. Recidivas em tuberculose e seus fatores de risco. Rev Panam Salud Publica. 2000;7(4):232-41. http:// dx.doi.org/10.1590/S1020-49892000000400004

22. Chaimowicz F. Age transition of tuberculosis incidence and mortality in Brazil. Rev Saude Publica. 2001;35(1):81-7. http://dx.doi. org/10.1590/S0034-89102001000100012

23. de Oliveira NF, Gonçalves MJ. Social and environmental factors associated with the hospitalization of tuberculosis patients. Rev Lat Am Enfermagem. 2013;21(2):507-14. http://dx.doi.org/10.1590/ S0104-11692013000200006

24. do Prado TN, Miranda AE, de Souza FM, Dias Edos S, Sousa LK Arakaki-Sanchez D, et al. Factors associated with tuberculosis by HIV status in the Brazilian national surveillance system: a cross sectiona study. BMC Infect Dis. 2014;14:415. http://dx.doi.org/10.1186/1471 2334-14-415

25. Torrens AW, Rasella D, Boccia D, Maciel EL, Nery JS, Olson ZD, et al Effectiveness of a conditional cash transfer programme on TB cure rate: a retrospective cohort study in Brazil. Trans $\mathrm{R}$ Soc Trop Med Hyg. 2016;110(3):199-206. http://dx.doi.org/10.1093/trstmh/trw011

26. Ranzani OT, Carvalho CR, Waldman EA, Rodrigues LC. The impact of being homeless on the unsuccessful outcome of treatment of pulmonary TB in São Paulo State, Brazil. BMC Med. 2016;14:41. http://dx.doi.org/10.1186/s12916-016-0584-8

27. Reis-Santos B, Gomes T, Macedo LR, Horta BL, Riley LW, Macie EL. Prevalence and patterns of multimorbidity among tuberculosis patients in Brazil: a cross-sectional study. Int J Equity Health 2013;12:61. http://dx.doi.org/10.1186/1475-9276-12-61

28. Gupta S, Granich R, Date A, Lepere P, Hersh B, Gouws E, et al. Review of policy and status of implementation of collaborative HIV TB activities in 23 high-burden countries. Int $\mathrm{J}$ Tuberc Lung Dis. 2014;18(10):1149-58. http://dx.doi.org/10.5588/ijtld.13.0889

29. Muniz JN, Ruffino-Netto A, Villa TC, Yamamura M, Arcencio R, Cardozo-Gonzales RI. Epidemiological aspects of human immunodeficiency virus/tuberculosis co-infection in Ribeirão Preto, Brazil from 1998 to 2003. J Bras Pneumol. 2006;32(6):529-34. http:// dx.doi.org/10.1590/S1806-37132006000600010

30. Ambadekar NN, Zodpey SP, Soni RN, Lanjewar SP. Treatment outcome and its attributes in TB-HIV co-infected patients registered under Revised National TB Control Program: a retrospective cohort analysis. Public Health. 2015;129(6):783-9. http://dx.doi org/10.1016/j.puhe.2015.03.006

31. Hino $P$, da Costa-Júnior ML, Sassaki CM, Oliveira MF, Villa TC, dos Santos CB. Time series of tuberculosis mortality in Brazil (1980 2001). Rev Lat Am Enfermagem. 2007;15(5):936-41. http://dx.doi. org/10.1590/S0104-11692007000500009

32. Silva Pda F, Moura GS, Caldas Ade J. Factors associated with pulmonary TB treatment dropout in Maranhão State, Brazil, from 2001 to 2010 [Article in Portuguese]. Cad Saude Publica. 2014;30(8):1745-54.

33. Middelkoop K, Bekker LG, Mathema B, Myer L, Shashkina E Whitelaw $A$, et al. Factors affecting tuberculosis strain success over 10 years in a high TB-and HIV-burdened community. Int J Epidemiol. 2014;43(4):1114-22. http://dx.doi.org/10.1093/ije/dyu044

34. Dowdy DW, Israel G, Vellozo V, Saraceni V, Cohn S, Cavalcante S, et al. Quality of life among people treated for tuberculosis and human immunodeficiency virus in Rio de Janeiro, Brazil. Int J Tuberc Lung Dis. 2013;17(3):345-7. http://dx.doi.org/10.5588/ijtld.12.0123

35. Dean AS, Zignol M, Falzon D, Getahun H, Floyd K. HIV and multidrug-resistant tuberculosis: overlapping epidemics. Eur Resp J. 2014;44(1):251-4. http://dx.doi.org/10.1183/09031936.00205413

36. Post FA, Grint D, Werlinrud AM, Panteleev A, Riekstina V Malashenkov EA, et al. Multi-drug-resistant tuberculosis in HIV positive patients in Eastern Europe. J Infect. 2014;68(3):259-63. http://dx.doi.org/10.1016/j.jinf.2013.09.034

37. Coeli CM. Sistemas de Informação em Saúde e uso de dados secundários na pesquisa e avaliação em saúde. Cad Saude Colet. 2010;18(3):335-6.

38. Santos NP, Lírio M, Passos LA, Dias JP, Kritski AL, Galvão-Castro $B$, et al. Completeness of tuberculosis reporting forms in five Brazilian capitals with a high incidence of the disease. $J$ Bras Pneumol. 2013;39(2):221-5. http://dx.doi.org/10.1590/S180637132013000200014 